\title{
Coulisses
}

Revue de théâtre

14 | Printemps 1996

Varia

\section{Jean-Luc Lagarce auteur - D'un texte à l'autre}

\section{(2) OpenEdition \\ 12 Journals}

Édition électronique

URL : http://journals.openedition.org/coulisses/4693

DOI : $10.4000 /$ coulisses.4693

ISSN : 2546-9460

Éditeur

Presses universitaires de Franche-Comté

\section{Édition imprimée}

Date de publication : 1 mai 1996

Pagination : 52

ISSN : 1150-594X

\section{Référence électronique}

« Jean-Luc Lagarce auteur - D'un texte à l'autre », Coulisses [En ligne], 14 | Printemps 1996, mis en ligne le 20 mars 2019, consulté le 24 octobre 2019. URL : http://journals.openedition.org/coulisses/ 4693 ; DOI : 10.4000/coulisses.4693

Ce document a été généré automatiquement le 24 octobre 2019.

Coulisses 


\section{Jean-Luc Lagarce auteur - D'un texte à l'autre}

\section{Lucien Attoun parle de quelques-unes des œuvres dramatiques de Jean-Luc Lagarce $^{1}$ :}

Personnellement, j'ai connu Jean-Luc Lagarce par la poste. Il était encore lycéen lorsqu'il m'a envoyé une pièce qui n'était pas inintéressante, mais pas aboutie. A France-Culture, on a eu un parcours très singulier, très personnel et permanent. La première pièce de Jean-Luc est passée en 1979 dans le répertoire. C'était Carthage encore. Pratiquement toutes ses pièces sont passées à France-Culture.

Le Voyage de Madame Knipper vers la Prusse orientale a été la première pièce vraiment montée dans des conditions normales au Petit Odéon par Jean-Claude Fall. La pièce a surpris beaucoup de gens mais elle n'a pas eu une vraie suite, c'est-à-dire une suite de carrière. C'était la pièce d'un tout jeune auteur, il aurait pu s'imposer tout de suite. Peut-être que Jean-Luc Lagarce n'était pas apparemment dans le mouvement des idées de l'époque, si on pense à son théâtre des années 80 . On se dit que c'est quelqu'un qui, de prime abord, ne s'occupe pas de la société, de la politique.

Quand on pense à Vagues souvenirs de l'année de la peste qui date de 1983, on est frappé par la modernité d'un certain nombre de thèmes; il s'agissait de la peste, mais on peut penser au Sida. Il y était aussi question de l'étranger, de l'exclusion.

J'ai été frappé par les deux ou trois versions - moi je n'en connais que deux - de Histoire d'amour qui est l'histoire de trois jeunes gens, à une époque qui pourrait tourner autour de mai 68 pour aller vite, et qui se retrouvent vingt ans plus tard, dans une autre pièce, puisque Derniers remords avant l'oubli est une sorte de prolongement. 
Dans la manière d'écrire, il a évolué. Vers la fin, il devient plus lyrique, parfois plus triste, plus nostalgique. C'est le cas dans la dernière pièce réellement aboutie de lui - pièce qui n'a pas encore été jouée mais qu'il a vue naître puisqu'elle a été mise en espace - qui a un titre assez long J'étais dans ma maison et j'attendais que la pluie vienne. C'est l'histoire d'un retour. Le retour du fils est l'une des obsessions de JeanLuc Lagarce (Retour à la Citadelle) fils ou pas, c'est un thème symbolique.

La dernière pièce dont j'ai pu lire la version écrite, Le Pays lointain, est émouvant et tragique. Cela ressemble un peu à un journal de bord et en même temps c'est une histoire de théâtre. Tout est transposé. Il y a ses amis, la mère, la famille. ${ }^{2}$

Jean-Luc Lagarce parle de quelques-uns de ses textes et mises en scène ${ }^{3}$ : Quand j'étais au lycée, je me rappelle que les professeurs voulaient toujours qu'on sache où se situait l'auteur. Dans Le Malade imaginaire, Béralde est censé être le représentant de Molière. Du coup, comme ça m'avait marqué au lycée, je me dis toujours "Quel est le personnage qui me représente?». J'ai monté Le Malade imaginaire et mon personnage sur le plateau, c'était plutôt Angélique que Béralde. Comme metteur en scène, je me sentais du point de vue d'Angélique.

Nous, les héros - diffusée en 1994 sur France-Culture - est une pièce qui se passe dans un théâtre.

Le nom de certains personnages vient du journal de Kafka. Kafka fait des allusions à du théâtre yiddish, qui se joue dans les brasseries, les restaurants. C'est un peu cet univers-là dont parle la pièce. Ce sont des gens qui vivent une histoire; il y a un rapport entre une troupe, la famille, l'errance. C'était cela qui m'intéressait.

NB : Nous, les héros sera mis en scène la saison prochaine par Olivier Py à La Rochelle.

1 Dans J'étais dans ma maison et j'attendais que la pluie vienne, Jean-Luc Lagarce donne la parole uniquement à des femmes.

C'est une pièce sur le retour. J'ai plutôt l'impression que ce sont les femmes qui attendent et les hommes qui partent. Je reviens à la tragédie. Je regarde la télévision et qu'est-ce que je vois? Des hommes qui se battent et des femmes qui ont l'air de pleurer. Ce n'est pas un discours féministe que je tiens. C'est l'histoire qui est comme ça. 


\section{NOTES}

1. Les propos de Lucien Attoun sont extraits d'une émission diffusée sur France-Culture en décembre 1995, émission consacrée à la rediffusion de Nous, les héros, précédée d'un entretien sur Jean-Luc Lagarce.

2. Jean-Luc Lagarce, Le Pays lointain, Les Solitaires Intempestifs, 1995.

3. Il s'agit d'extraits d'interviews diffusées lors de l'émission de Lucien Attoun, voir note 1. 